\title{
POSSEIROS E POLÍTICA - GOIÁS NOS ANOS ‘60
}

\author{
Cléria Botêlho da Costa \\ (Depto. de História da UnB)
}

\begin{abstract}
RESUMO: Este texto mostra que Goiás é uma área de grande extensāo geográfica, direcionada para absorver os excedentes populacionais dos grandes centros urbanos do país e lhes oferecer produtos agrícolas. Caracteriza-se então, como área de expansão agrícola, parte de uma política de "ocupação e interiorizaçāo" do país que objetivava a fixação do homem a partir do Centro Oeste. Nos anos 60, Goiás foi ocupado por posseiros que viviam a contradição de serem proprietários reais e nāo proprietários jurídicos da terra que ocupavam. Esta contradiçāo vivida pelos posseiros no nível das relações de produção foi capitalizada por partidos políticos o que thes possibilitou atuarem como agentes políticos de um novo projeto de desenvolvimento.
\end{abstract}

ABSTRACT: This article discusses the Brazilian state of Goiás, an area of vast geographical extension which absorbs the populational excess of the country's urban centers as well as supplying agricultural products to these cities. Characterized as an area of agricultural expansion, this state is geared toward a policy of "ocupation and interiorization" aimed at establishing thriving rural settlements in the Midwestern region of Brazil. During the 1960s, Goiás was occupied by posseiros who lived the contradiction of being the actual. but not the legal owners of the land they occupied. This contradiction, was capitalized by political parties, enabling them to participate politically in a new development project.

PALAVRAS-CHAVE: Goiâs, Posseiros, Política, Reforma Agrária, Ligas Camponesas.

KEY-WORDS: Goiás, Posseiros, Politics, Agrarian Reform, Peasant Leagues.

A caracterização de Goiás como frente de expansão se faz há muitos anos, associando-o à produção - agropecuária subsidiária das frentes pioneiras do café, junto com Minas Gerais e Mato Grosso (DAYRELL, 1973, p. 4).

Em 1945, o governo federal criou em Ceres, município goiano, a Colônia Agrícola Nacional de Goiás
(GANG) como parte de uma política de "ocupação e interiorização do país", objetivando a fixação do homem a partir do Centro-Oeste - a "Marcha para o Oeste". Essa foi a primeira experiência de colonização planejada em Goiás, constituindo-se em pólo de atração para migrantes e favorecendo o aumento da força de trabalho disponível para a agricultura. Em 
1946, contava com 900 habitantes; em 1950, esse número atingia 29 522; em 1960 quando o município já era um dos líderes da produção agrícola goiana, a população atingira a cifra de 42802 habitantes (DAYRELL, 1973, p. 24).

De 1950 a 1960, o governo federal, dando continuidade àquela política de "ocupaçāo e interiorizaçāo", criou três obras de grande vulto, que muito contribuíram para a expansão da fronteira agrícola goiana: as rodovias Belém-Brasília e Transamazônica. A importância das rodovias reside em terem favorecido a interligação dos centros urbanos, o aumento da produção agrícola, o surgimento de novos núcleos urbanos e o crescimento demográfico. A construção de Brasília em pleno território goiano constitui não só mercado para os produtos agrícolas do estado como amplia sua densidade demográfica. O governo Mauro Borges (1960/1964) retomou a política de colonização agrícola, criando novos núcleos.

No período de 1950 a 1960, o número de migrantes para Goiás foi de aproximadamente 461619 pessoas, com uma taxa de migração de $23,6 \%$ e uma taxa de crescimento populacional de $4,9 \%$ ao ano, enquanto a do país era de 3,2\% (Conjuntura Econômica, 1962, p. 26). A economia do estado naquele período apresentou crescimento superior à média nacional, com o PIB crescendo a uma taxa geométrica de $10,5 \%$ ao ano - a taxa similar nacional era de 6,0\% (Conjuntura Econômica, 1962, p. 31).

Tal crescimento econômico goiano se deve à exportação de produtos agrícolas para outras áreas do país, como foi destacado por Leo WAIBEL (1974, p. 227).

O significado da política de "interiorizaçāo e ocupação" do país pode ser percebido de formas de expansāo do capitalismo no país, sob a direção do estado, tendo em vista criar uma infra-estrutura em Goiás - fundamentalmente, rodovias - (OLIVEIRA, 1975, p. 36), além de dirigir as correntes migrató- rias, atenuando os problemas e tensões sociais de centros urbanos no país (ESTERCI, 1972). Por se tratar de uma área de grande extensão geográfica, direcionada para observar os excedentes populacionais dos grandes centros urbanos e thes oferecer produtos agrícolas, Goiás foi ocupado por posseiros que faziam uso privado das abundantes terras devolutas. Nessa medida, os posseiros vivenciavam uma forte contradição: eram proprietários reais e não proprietários formais das terras que ocupavam (MARTINS, 1975, p. 46).

Essa contradição se agravava na conjuntura dos anos 60: a abertura de grandes estradas $e$ a construçāo de Brasília valorizavam as terras, donde os possciros passaram a concorrer seja com proprietários absenteístas, seja como grilciros, donde a luta pela posse da terra e o agravamento dos conflitos sociais no campo goiano.

Os estabclecimentos ocupados, em 1950, correspondiam a $28,98 \%$ do total de estabelecimentos agrícolas cm Goiás - 63 736. Em 1960, csse percentual atingira $16,75 \%$, num total de 111015 estabelccimentos (Censo Agrícola de Goiás, $1950 \mathrm{e}$ 1960). Constata-se pela tabela 1 que, no período de 1950 a 1960, os cstabelecimentos ocupados se concentravam na faixa de 0 a 100 ha. Isto revela qual a ocupação se fazia por posseiros que dispunham, na maioria dos casos, de pequenas porções de terra, dedicando-se a uma cultura de subsistência e destinando uma parte da produçāo ao mercado. Segundo Martins, tal excedente não deve ser visto como "sobra do consumo" e sim como o produto resultante da utilização de fatores excedentes principalmente, terra e trabalho (MARTINS, 1975, p. 65).

Quanto ao fato de os posseiros se concentrarem em pequenos estabelecimentos, deve-se considerar que conduziam suas atividades com base no trabatho familiar, dispondo apenas de alguns instrumentos de trabalho mais rudimentares. Além disso, a posse por ocupação nas regiōes mais novas tende a 
TABELA 1

Distribuição dos Estabelecimentos Agrícolas de Goiás quanto ao

Grupo de área e Área Total - 1950 - 1960.

\begin{tabular}{|c|cc|cc|cc|cc|}
\hline Grupo de Área (Ha) & \multicolumn{3}{|c|}{ Número de Estabelecimentos } & \multicolumn{4}{c|}{ Área Total (Ha) } \\
\hline & 1950 & $\%$ & 1960 & $\%$ & 1950 & $\%$ & 1960 & $\%$ \\
\hline $0-100$ & 33914 & 53,22 & 69850 & 62,67 & 9002400 & 37,0 & 2397177 & 9,5 \\
\hline $101-1000$ & 25012 & 39,24 & 36151 & 32,56 & 4263844 & 17,5 & 8317508 & 33,0 \\
\hline $1001 \mathrm{a}+$ & 4810 & 7,54 & 5284 & 4,77 & 11034386 & 45,5 & 14471489 & 57,50 \\
\hline Total & 3736 & 100,0 & 111015 & 100,0 & 14300630 & 100,0 & 25186174 & 100,0 \\
\hline
\end{tabular}

Fonte - IBGE, Censo Agrícola de Goiás - 1950 - 1960.

reproduzir a mesma estrutura agrária existente em regiões mais antigas, onde um grande número de pequenos proprietários detém ínfimas parcelas de terra.

Por outro lado, o decréscimo da área dos estabelecimentos ocupados pode ser compreendido pela forte especulação imobiliária ocorrida naquele período, face, principalmente, à construção das rodovias e da nova capital. Diante desse fenômeno, o possei- ro é forçado a entregar as terras aos proprietários absenteístas ou a reduzi-las consideravelmente.

Para o estado como um todo, a tendência é a de diminuição do número dos estabelecimentos ocupados. Em sua maior parte, eles se localizam em área de natureza pública, como mostra a tabela 2 , num percentual de $70 \%$ em 1960.

Na maioria desses estabelecimentos, a força de trabalho básico era representada pelo responsável e

TABELA 2

Natureza da propriedade da Terra em Goiás - 1960

\begin{tabular}{|c|c|}
\hline Especificação & $\%$ \\
\hline Privada & 30 \\
\hline Estado & 70 \\
\hline Total & 100 \\
\hline
\end{tabular}

Fonte - Instituto de Desenvolvimento Agrário de Goiás - 1950 - 1960. 
TABELA 3

Estabelecimentos Ocupados, Grupo de área e Área Total - 1950 - 1960.

\begin{tabular}{|c|cc|cc|cc|cc|}
\hline Grupo de Área (Ha) & \multicolumn{3}{|c|}{ Número de Estabelecimentos } & \multicolumn{4}{c|}{ Área Total (Ha) } \\
\hline & 1950 & $\%$ & 1960 & $\%$ & 1950 & $\%$ & 1960 & $\%$ \\
\hline $0-100$ & 18075 & 99,99 & 13462 & 74,6 & 376433 & 10,2 & 389526 & 16,6 \\
\hline $101-1000$ & 1 & - & 4236 & 23,6 & 2327967 & 63,4 & 1390380 & 57,9 \\
\hline $1001 \mathrm{a}+$ & - & - & 327 & 1,8 & 996217 & 26,4 & 609521 & 25,5 \\
\hline Total & 18076 & 100,0 & 18025 & 100,0 & 3670617 & 100,0 & 2398427 & 100,0 \\
\hline
\end{tabular}

Fonte - IBGE, Censo Agrícola de Goiás - 1950 - 1960.

por membros não-remunerados da família, que expressavam $84,8 \%$ (1950) e $89 \%$ (1960) do total da população ocupada, como se vê na tabela 3:

Em termos nacionais, a força de trabalho ativa predominante nos estabelecimentos agrícolas ocupados tinha composição semelhante, compreendendo $75,7 \%$ em 1950 e $84,6 \%$ em 1960 do total da população ativa naqueles estabelecimentos, que cra de 754 685 e 1219174 trabalhadores respectivamente (Censo Agrícola do Brasil, 1960 a 1970).

A tendência do estado, como um todo, é a de diminuição da força de trabalho nos estabelecimentos ocupados o que pode ser explicado por se manterem no nível da cultura de subsistência ou de pequena produção de excedentes econômicos, sem disporem de condiçōes para enfrentar a concorrência no nível de mercado com os grandes produtores. Assim, eram chamados ao mercado da força de trabalho, tornando-se assalariados e reduzindo ainda mais a força de trabalho dos estabelecimentos ocupados.

A compreensão de Goiás como área de expansão agrícola deve ser buscada, ainda, no próprio modelo de desenvolvimento econômico e político adotado pelo país nos anos 60 , que tinha como base a industrialização. Daí, aquele estado ser chamado a intensificar sua agricultura a fim de oferecer a baixo custo força de trabalho c produtos de subsistência para os centros industriais do país (Diario Oficial de Goiás, 20.3.1962).

É a partir da posição que os posseiros ocupavam nas relações de produção $\mathrm{cm}$ Goiás e das relações sociais que mantinham com os demais grupos, que eles se transformaram em força social.

$O$ ano de 1953, quando foi criada a primeira associação rural em Goiás (TOSCANO, p. 130), representa o primeiro momento da história dos movimentos rurais na área. É na conjuntura dos anos 60 que tais movimentos chegaram ao apogcu, funcionando 200 sindicatos rurais espalhados $\mathrm{em}$ todo o estado, 20 associações rurais com presença semelhante e $13 \mathrm{Li}$ gas Camponesas nos municípios de Dianópolis, Natividade e Rialma (Diário do Congresso Nacional, 25.10.1963).

A contradição vivida pelos posseiros no nível das relações de produção foi capitalizada pelo $\mathrm{PCB}$, no nível legal (alianças com partidos políticos) e clan- 
destino (arregimentaçāo e organização de camponeses, operários e estudantes) (TOSCANO, p. 130). Isto lhes possibilitou atuarem como agentes políticos de um novo projeto de desenvolvimento.

Tal expansão do movimento popular no campo em Goiás no início dos anos 60 se relaciona com o governo Mauro Borges, que procurou manter o quadro de relaçōes sociais de dominaçāo, empreendendo uma luta política contra as velhas estruturas agrárias via proposta de Reforma Agrária. Esta luta foi marcada por uma linguagem nacionalista, congregando estudantes, operários, grupos dominantes e grupos dominados no campo.

O movimento dos posseiros, de 1961 a 1962, caracterizou-se pela expansão e fortalecimento de suas organizações.

O estado, com vistas a institucionalizar os conflitos do campo, iniciou uma campanha de sindicalização rural e transformação das associaçōes rurais já existentes em sindicatos chegando a existir no período 200 sindicatos rurais ${ }^{l}$.

Os posseiros, por seu turno, conseguiram que fossem aprovados na assembléia Legislativa vários decretos e leis abrangendo, por exemplo, a permissão de venda de terras devolutas e a concessão de títulos definitivos de terras. Essas vitórias, apesar de suas limitaçōes, serviram para estimular e fortalecer o movimento popular no campo.

Em julho de 1962, realjzou-se o $1^{\circ}$ Congresso Operário-Estudantil-Camponês de Goiás, em Goiânia, com a participação de 1200 pessoas - em sua maioria trabalhadores rurais. Nele, os grupos dominados do campo ficaram sob a direção do PCB,

1. O que pode ser visualizado num trecho do discurso do Secretário de Trabalho e Ação Social do governo Mauro Borges: "A partir de maio, o estado inicjará uma forte campanha de sindicalização tural em massa e de transforma. ção das associaçōes rurais já existentes em sindicatos". (Dicirio Oficial de Goiás, 20.3.1962). manifestando-se por sua legalidade "como único partido que é fiel aos camponeses" " $11^{\circ}$ Congresso Operário-Estudantil-Camponês”. Revista Brasiliense, 44, p. 98).

Em outubro do mesmo ano, esses grupos elegeram um primeiro representante para a Assembléia Legislativa, José Porfírio, através do $\mathrm{PCB}{ }^{2}$.

Suas principais reivindicações abrangiam a entrega dos títulos de terras aos posseiros, a luta anti-imperialista e por liberdades democráticas (Revista Brasiliense, 44, p. 98). A Reforma Agrária, nesses termos, devia ser feita por vias legais, através da aliança entre posseiros no parlamento, onde deviam se mostrar "contra as estruturas agrárias tradicionais" $\mathrm{e}$ "contra a estagnação econômica mantida por uma oligarquia agrária semi-feudal" (Diário Oficial, 25.10.1962).

Trata-se de reivindicaçōes de natureza coletiva, situadas no nível das macro-decisōes, intimamente ligadas ao estado. Ao contrário do que sustenta Weffort sobre a maior relevância das relações políticas entre indivíduos em comparação às relações entre classes sociais distintas (WEFFORT, 1965, p. 67), observa-se nesse contexto a importância das relações entre grupos ou classes sociais.

Em agosto de 1962, foi criada em Dianópolis a primeira Liga Camponesa em Goiás. Sua origem está ligada a um grupo de estudantes e profissionais nordestinos liderados por Clodomir de Morais, membro dissidente do grupo de Francisco Julião em Pernambuco (Última Hora, 23.6.1962). Ele fora expulso do PCB em junho do mesmo ano, acusado de ser um aventureiro, buscando, a partir de entāo, as influências políticas de Cuba e China (Diánio do Congresso Nacional, 10.6.1963).

2. Sua veiculação ao PCB é insinuada no IPM 709 ( $O$ comunismo no Brasil. vol. IV, pp. 387-393) e no artigo: José Bernardes Félix Souza. "As Eleiçōes Goianas". Revista Brasiliense de Estudos Políticos, 1964, p. 281. 
As Ligas Camponesas privilegiavam a guerrilha como forma de luta, tema presente no seguinte documento:

O Regimento Interno do Dispositivo Revolucionário das Ligas Camponesas aponta a sua ação dentro da doutrina de "A Guerra das Guerrilhas", de "Che" Guevara (cap. I), que desejava as "Sierras Maestras" do Processo Revolucionário Marxista no Brasil pela linha dura e estilo chinês e cubano.. O prefácio desse regimento está assim redigido: "Prezados Companheiros da Direção Nacional - saudações fraternais - $O$ presente documento não revela nenhuma negaçāo de nossa parte à grande tarefa que fomos chamados a cumprir: destruir pela luta armada o Governo burguês decadente c criar o governo revolucionário..." (Di. ário do. Congresso Nacional, 1.6.1963).

Em novembro de 1962, Morais enviou a Cuba um grupo constituído por estudantes e trabalhadores rurais, com o objetivo de reforçar o movimento popular no campo e promovê-lo no âmbito internacional (Diário do Congresso Nacional, 25.11.1963).

Observa-se, então, que o período de 1961/1962 foi de expansão e fortalccimento do movimento dos posseiros, seja através de organizaçōes atreladas ao estado, seja via organizaçōes independentes.

Em 1963/1964, o movimento dos posseiros enfrentou problemas de ordem política c organizacional como divergências quanto às formas de sua ação política e fragmentação das organizações, ao mesmo tempo, intensificaram-se formas de luta que extrapolavam a legalidade burgucsa - invasōes, greves e grupos de resistência'armados.

Desde o $2^{\circ}$ semestre de 1962 , quando foram criadas as Ligas Camponesas em Goiás, a prática política dos posseiros passou a ter duas orientações: uma reformista, apregoada pelo PCB, e outra com apro-

3. O próprio Morais afirmou que "O Setor Armado se Compunha Essencialmente de Dissidentes do PCB". Aspásia Camargo, op cit., p. 182. ximações revolucionárias ${ }^{3}$, difundida pelo $\mathrm{PC}$ do $\mathrm{B}$. A primeira sc desenvolveu fundamentalmente nos sindicatos e a segunda nas Ligas Camponesas $c$ associações.

Face à campanha de sindicalização rural, levada a cabo pelo estado, a maior parte das organizaçōes dos posseiros foi transformada em sindicatos, organizações atreladas ao estado. Como instrumento independentes, restaram apenas as Ligas Camponesas e algumas associaçōes. Essa fragmentação das organizaçōes, contudo, não limitou a importância da luta dos posseiros em Goiás: mesmo quando organizados em sindicatos, representavam uma força dinâmica na nova tendência que se apresentava nos movimentos rurais em todo o país e suas lutas continuaram a ser intensificadas.

Em 1963, os posseiros passaram a utilizar como formas de luta para obterem a Reforma Agrária invasões, greves e tentativas de guerrilhas. As invasões se faziam em torno de propriedades privadas e foram uma forma de luta cmpreendida pelos grupos dominados (ocupantes) para enfrentarcm os grupos dominantes (proprietários rurais), como fica patente no seguinte documento: “...Em Cangica no Município de Formosa, 80 famílias invadiram as terras de um fazendeiro que pelo que sc sabe, não as usava totalmente, mas eram de sua propriedade" (CPI $5 I$, maio de 1965).

O objetivo das invasōes era pressionar o Parlamento para realizar a proposta de' Reforma Agrária, como se observa na seguinte declaraçāo: “... o que nóis queria mesmo era que o Governo cumprisse o que tinha prometido a nóis, o papel de nossas terras e a melhoria da nossa vida..."'.

As principais áreas de invasão de terras foram a regiāo de Trombas e Formoso, Gurupi, Cristalina, Araguaína e Araguacema (CPI 5l, maio de 1965).

4. Entrevista, jan. 1980, conservado o nível de fala do depoente. 
As greves ocorreram, fundamentalmente, no Combinado Agro-Urbano de Arrais, colônia agrícola do estado, sobre o que fala um entrevistado:

...levaram nóis para o combinado de Arrais, prometendo um pedaço de terra e a promessa nunca foi cumprida. Lá também faltava até o que comer. Por isso tudo, várias vez nóis fiquemo até sete dia sem trabalhar...5.

Também as greves, portanto, tiveram como objetivo pressionar o estado pela posse da terra e por melhores condições de trabalho.

Quanto aos grupos de resistência armada, tivemos informaçōes sobre a existência de $18 \mathrm{em}$ todo o estado (Diário do Congresso Nacional, 26.9.1967). Foram mais uma forma de luta utilizada pelos grupos dominados no enfrentamento direto com os grupos dominantes, conforme depoimentos de ocupantes:

No município de Natividade quando a coisa apertou, moça nóis arriunimos um grupo de 50 home com os pouco de arma que nóis tinha e enfrentemo os capanga dos "home" que queriam por nóis fora de nossas terra'.

Em Araguacema, a coisa foi mais preta, dona. Nóis enfrentamo os capanga e até a poliça, lá teve tiroteio $\mathrm{c}$ algumas morte... ${ }^{7}$.

Esses núcleos de resistência se localizaram fundamentalmente em Natividade, Rialma, Gurupi, Araguacema e Xambioá.

Quanto às guerrilhas, importa destacar que, sob a liderança de Morais, um grupo de militantes criou o campo de treinamento de guerrilhas de Caatingueiro em Dianópolis, município do norte goiano, hoje, Tocantins com vistas à insurreiçāo armada. Esse

5. Entrevista, dez. 1979, com ex-colono de Combinado.

6. Entrevista realizada em 25.5.1979 com um dos líderes do movimento dos posseiros em Goińs.

7. Entrevista realizada em 15 de junho de 1960 , também com um dos líderes do movimento dos posseiros. campo, contudo, enfrentou vários problemas: grupos de estudantes gojanos e pernambucanos não se adaptaram bem ao simulacro de guerrilha e os grupos dominados do campo não chegaram a assumí-las totalmente. Em dezembro de 1963, as Forças Armadas intervieram, várias pessoas foram aprisionadas e suas armas foram recolhidas".

Os slogans "Reforma Agrária na lei ou na marra" e "Morte aos latifundiários" ilustra bem essa última lendência.

É necessário ressaltar que, em janeiro de 1963 , com o plebiscito e a restauração do presidencialismo, Goulart se comprometeu a cumprir um programa de reformas, sendo a agrária priorizada. Em março desse ano, o Congresso aprovou o Estatuto do Trabalhador Rural e a Lei 4214 , assinada por Goulart e seu ministro do Trabalho, permitiu a multiplicação de sindicatos rurais em todo o país.

Deduz-se que só quando o movimento popular no campo dispõe de condições objetivas para se tornar de âmbito nacional e o poder público anunciou a reforma agrária como medida prioritária do governo é que a luta pela última em Goiás se tornou mais ousada. Noutros termos, a luta pela Reforma Agrária não podia se radicalizar antes que o movimento rural tomasse uma dimensāo nacional.

Em março de 1963, as Ligas Camponesas em Goiás criaram um comitê regional, que manteve forte ligação com o Comitê Nacional criado em outubro do mesmo ano, em Pernambuco (Diário Oficial de Goiás, 20.9.1963).

No início do ano seguinte, o movimento dos grupos dominados em Goiás e em todo país se apagou, num contexto geral de crise do estado. É com base nas condições estruturais de produção que tentarei perceber a subordinação política dos grupos dominados do campo ao estado, feita essencialmente por meio da ideologia e dos aparelhos repressivos (exér-

8. Diário do Congresso Nacional, 25.10.1963. 
cito, polícia, etc), que tiveram um papel fundamental para colocar a serviço do estado o apoio social necessário à sua sustentaçāo.

A subordinação ideológica dos grupos dominados fica evidenciada quando aceitaram uma proposta de Reforma Agrária que não alteraria a propriedade privada da terra, beneficiando um númcro muito restrito de posseiros e mantendo intactas as relaçōes de poder e de çlasse e a aliança com setores dos grupos dominantes (a aliança operária-estudantil-camponesa), como mostra o seguinte documento:

Os estudantes, camponeses, operários, parlamentares e o povo em geral reuniram-se ontem na sede da Associação Comercial, sob o patrocínio da Uniāo Goiana dos Estudantes Secundaristas, na defesa das riquezas do estado e contra o truste de níquel...".

Essa aliança foi firmada em 1961 e as aparências eram mais fortes c se impunham, fazendo com que os grupos dominados não perccbessem o real significado da mesma enquanto dominaçāo de classe, isto é, que a aliança se fazia sob a hegemônica dos grupos dominantes, os quais tinham sua representação no estado, com vistas a servir-lhe de apoio social para assegurar sua dominação.

Pode-se ainda notar tal subordinação idcológica dos grupos dominados do campo quando seu representante no Parlamento, José Porfírio, antes se de tornar oposição, parecia reforçar a confiança nos grupos dominantes, como expresso num seu discurso: "[...] o trabalhador do campo continua aceitando o Govcrnador Mauro Borges porque é um dos poucos governadores de estado que tem sido um defensor autêntico do trabalhador rural" (Jornal $4^{\circ}$ Poder, dezembro de 1977).

Além da subordinação ideológica, os posseiros foram submetidos pelos aparelhos repressivos do estado, como é ilustrado pelo depoimento a seguir:

9. Idem, 20.2.1963.
O Presidente da Associação dos Lavradores de ltaporanga declara que desde 1947, estamos plantando a terra e agora somos 147 familias em 9 léguas e $4 \mathrm{~km}$, que perdemos tudo por influência e pressão de grupos políticos. Em julho de 1962, os fazendeiros N.E.L., com o auxílio da polícia do estado, obrigaram os posseiros a vender suas terras. Houve luta, não entregamos nossas terras passivamente, mas a polícia tinha muitas armas (BORGES, 1965, p.36).

Ou ainda nas palavras do proprio governador:

As agitaçōes mais encontradas em curso por meu governo c proteladas em suas soluçōes por administraçōes passadas, e outras promovidas por elementos suspeitos para tumultuar a vida do cstado, como os de Trombas, Formoso, Porangatu, Juçara, Salobrinha, Canuanā, Gurupi, foram energicamente debeladas, estabclecendo-se, por vias legais e atendendo a princípios sociais, a verdadeira paz social na maioria das localidades acima referidas. As limitadas operações de guerrilhas de Dianópolis, sofregamente exploradas por indústrias de anticomunismo c dirigidas por elementos de outras regiōes, foram desbaratadas e liquidadas pela pronta e firme ação de polícia militar do cstado, com a cooperação de autoridades militares (Diário do Congresso Nacional, 25.9.1968).

Assim sendo, a partir do movimento em que os grupos dominados no campo accitaram a aliança operário-cstudantil-camponesa, quando reforçaram sua confiança nos grupos dominantes ou foram expulsos de suas terras pela açāo dos proprietários rurais com o concurso da polícia ou do exército, fica evidenciada sua subordinação ao estado.

O estado $\mathrm{cm}$ Goiás cra o maior proprietário fundiário na conjuntura em estudo $-88 \%$ das terras. Face à crise de hegemonia, buscou sua legitimação no campo, interferindo e controlando a propriedade da terra, subordinando a ação dos grupos dominados através da ideologia ou dos aparelhos repressivos. Essa subordinação se fez ora apoiando a ação dos grileiros, ora a dos proprietários formais da terra. Ao mesmo tempo que o estado reprimia a ação conjunta dos grupos dominados, estimulava e orientava a organização dos sindicalistas rurais. 
A subordinação dos grupos dominados do campo ao estado não foi total, o que fica evidente quando se percebe que mesmo os grupos dominados participando da Aliança Estudantil-Operário-Camponesa faziam algumas restrições a ela, como fica patente numa entrevista: "Nóis nāo aceitava ajuda de deputado e de estudante, nas coisas que nóis fazia, porque movimento de camponês é de camponês e de estudante é de estudante ${ }^{10 "}$. 1980.

10. Entrevista realizada com posseiro, em dezembro de

\section{Bibliografia}

AMIN, Samir \& VIRGgOPOULOS, Kostas. A Questão Agräria e o Capiralismo. Rio de Janeiro, Paz e Terra, 1984.

ARAÚJO, José Brás. "Cajo Prado Júnior c a Quesıāo Agrária no Brasil". In: Revista Temas, 1982, pp. 25-38, vol. I.

BORGES, Mauro. O golpe em Goiás. Rio de Janeiro, Civilização Brasileira, 1965.

DAYRELL, Eliane G. A Colónia Agrícola Nacional de Goiás. Dissertação de Mestrado em História apresentada ao Depto. de História da UFGO. Goiânia, Mimeografado, 1973.

ESTERCI, Neide. O Mito da Democracia no País das Bandeiras. Mimeografado, 1972.

GRZYBOWSKI, Candido. Caminhos e Descaminhos dos Movimentos Sociais no Brasil. Rio de Janeiro, Vozes, 1987.

MARTINS, José de Sousa. Capitalismo e Tradicionalismo. São Paulo, Pioneira, 1975.

1989

Camponeses e Política no Brasil. Rio de Janeiro.

Vozes, 1986.
Ou ainda quando a prática política daqueles grupos não se limitava às formas legais (participação no Parlamento, Congressos, etc.), abrangendo o espaço da ilegalidade - invasões, grupos de resistência armados - perdendo-se a imagem do estado como provedor das "necessidades coletivas": "O Presidente da Associação dos Lavradores de Crixás coloca que os lavradores daquela região, diante da falta de assintência e da forte repressão do governo, não esperam mais nada do governador Mauro Borges"11.

11. Diário Oficial de Goias, dezembro de 1948.

A Militarização da Questão Agrária no Brasil. Rio de Janciro, Vozes, 1984.

OLIVEIRA, Francisco de. "A Economia Brasileira: Crítica da Razīo Dualista". Seleçôes CEBRAP, 1, 1975, pp. 25-32.

" $1^{\circ}$ Congresso Operário-Estudantil-Camponês". Revista Brasiliense, 44, 1965, pp. 10-20.

REYDON, Bastiaan el alli. Reforma Agrária da Nova República. São Paulo, Cortez, 1984.

RIBEIRO, Ivan Otero. Agricultura Democracia e Socialismo. Rio de Janciro, Paz e Terra, 1987.

TAVARES, José Vicente. Matuchos: uma Exclusäo e Luta. Rio de Janeiro, Vozes, 1993.

TOSCANO, Gabriela \& CASTRO, Nádia. "Determinantes Sócioeconômicos do Radicalismo Eleitoral: o Caso de Goiás". Revista de Administração Püblica 1(7), 1976, pp. 130-142.

WAIBEL, Leo. "Unu Viagern de Reconhecimento ao Sul do Goifs". Revista Brasileira de Geogrufia, 10, 1974, pp. 227-300.

WEFFORT, Francisco Corrêa. "Política de Massas". In: Políitca e Revolução Social no Brasil. Rio de Janeiro, Civilização Brasilcira, 1965.

Endereço da autora: SQN 305 Bloco F apto. 508 - CEP 70344-060 - Brasilia • DF - Brasi! 